\title{
Treatment of Toenail
}

\section{Onychomycosis using Laser Pharmacology ${ }^{\mathrm{TM}}$}

\author{
Kerry Zang ${ }^{1}$, Travis M Sammons ${ }^{2 *}$ and Steve Shanks ${ }^{3}$ \\ ${ }^{1}$ Arizona Institute of Footcare Physicians, Mesa, AZ 85204, United States \\ ${ }^{2}$ Erchonia Corporation, Melbourne, FL 32904, United States
}

Received: 09 November, 2020

Accepted: 27 January, 2021

Published: 29 January, 2021

*Corresponding author: Travis M Sammons, Erchonia Corporation, Melbourne, FL 32904, United States, Tel: 888-242-0571; Fax: 321.473.1608;

Email: tsammons@erchonia.com

Keywords: Onychomycosis; Nonthermal laser; Mycological cure; Complete cure; Clinical trial; Laser pharmacology $^{\text {TM }}$

https://www.peertechz.com

Check for updates

\begin{abstract}
Background: Onychomycosis is a common infection of the nail bed that can negatively affect patient quality of life. The complete cure rate for systemic drugs is $23-$ $37 \%$ while the complete cure rate for topical drug therapy with efinaconazole is $27.7 \%$. Laser Pharmacology ${ }^{\text {TM }}$ presents a promising alternative using a dual-diode laser employing wavelengths of $635 \mathrm{~nm}$ and $405 \mathrm{~nm}$ to create a drug-like response in living tissue (Erchonia ${ }^{\circledR}$ Lunula Laser $^{\circledR}$; Erchonia Corporation. Melbourne, FL). The purpose of this clinical study is to assess the safety and efficacy of mycological and complete cure rates of the dual diode nonthermal laser.
\end{abstract}

Methods: Enrolled subjects $(N=20)$ had onychomycosis affecting the great toenail, confirmed by a positive mycological culture. Subjects were predominantly female (70\%) with a mean (SD) age of 59.9 (9.0) years. Affected toenails were treated with 12-minute laser light sessions, each week for 4 weeks, then one session at $3,5,7,9$ and 11 months. Study assessments were completed at $3,5,7,9,11,12$ and 14 months.

Results: Most subjects achieved a Clinical Cure $(n=14,70 \%)$ and Mycological Cure $(n=19,95 \%)$ of the affected great toenail. At 12 months, most subjects also achieved Clinical Efficacy ( $n=18,90 \%)$, Mycological Cure $(n=19,95 \%)$ and unaffected New Nail Growth $(n=20,100 \%)$.

Conclusion: This study confirms the safety and effectiveness of a non-thermal $635 \mathrm{~nm} / 405 \mathrm{~nm}$ dual-diode laser device for providing mycological and complete cure rate in onychomycosis-affected toenails following four weekly and five bi-monthly treatment sessions.

Trial registration: ClinicalTrials.gov Identifier NCT03066336, registered 02/28/2017, https://clinicaltrials.gov/ct2/show/NCT03066336

\section{Abbreviations}

FDA: Food and Drug Administration; ATP: Adenosine Triphosphate; NO: Nitric Oxide; ROS: Reactive Oxygen Species; NOX: Nicotinamide Adenine Dinucleotide Phosphate Oxidase; FAD: Flavin Adenine Dinucleotide; GAPDH: Glyceraldehyde-3Phosphate Dehydrogenas; ITT analysis: Intention to Treat; SD: Standard Deviation

\section{Introduction}

Onychomycosis is a common infection of the nail bed, most often caused by fungal dermatophytes (90\%), but may also be caused by molds ( $8 \%$ ) and yeasts $(2 \%)$ [1]. Risk factors include immunosuppression, advancing age, diabetes, psoriasis and nail abnormalities [2]. It can also result from trauma to the nail unit which breaks the hyponychial seal and allows organisms to enter the nail bed. Over time, the nail becomes increasingly discolored, thickened, and unsightly. Consequently, onychomycosis can have a significant impact on the quality of life of affected individuals [3,4], especially among women [5]. As shoes provide warm and moist conditions, onychomycosis affects toenails more than fingernails. In North America, the prevalence of onychomycosis is $13.8 \%$ [6].

Current drug therapies include primarily systemic and topical antifungal agents. Studies have shown the complete cure rate for systemic drugs range from $23-37 \%$. Due to systemic toxicity and various other disadvantages associated with oral therapy like gastrointestinal and hepatotoxicity, topical therapy is commonly used [7]. Topical drugs are easier to apply and show less adverse effects, but the keratin rich structure of the nails results in improper penetration. Due to poor penetration of topical therapy across the nail plate, research is focused 
on different chemical, mechanical and physical methods to improve drug delivery [7]. Efinaconazole and tavaborole have shown some improvement in the transungual drug delivery as they do not bind to the keratin present in the nails [8]. This is the result of the development of Polypseudorotaxanes based nail lacquer with the incorporation of penetration enhancer which is able to achieve a high rate of drug penetration and retention [9]. The complete cure rate for FDA approved topical drug therapy efinaconazole is $15.2-17.8 \%$ [10]. Several thermal lasers are available for treating onychomycosis but only cleared to temporarily increase the amount of clear nail, and lack published data showing mycological or complete cure. Disadvantages of thermal lasers include mild treatmentrelated burning or pain and should be used with caution with patients that are insensate, such as patients with diabetes and peripheral vascular dysfunction. Additionally, thermal lasers cannot provide total coverage to the nail plate, subcutaneous tissues, and the germinal layer. This is crucial as the matrix extends approximately $5 \mathrm{~mm}$ beneath the proximal nail fold.

Laser Pharmacology ${ }^{\mathrm{TM}}$ is a series of nonthermal interactions caused by laser photons that produce a change in physiology through similar, if not the same, biological pathways of pharmaceuticals. This principle has previously demonstrated effectiveness for several conditions including reducing low back pain [11], neck and shoulder pain [12], plantar fasciitis [13], musculoskeletal pain, post-surgical pain [14], and noninvasive body contouring [15]. All of which have been granted an FDA $510(\mathrm{k})$ clearance for their respective indications.

The primarily attribute for laser to produce antifungal activity is the laser wavelength. A novel laser device uses a dual-wavelength design incorporating $635 \mathrm{~nm}$ (red) and 405nm (violet) (Erchonia ${ }^{\circledR}$ Lunula Laser ${ }^{\circledR}$; Erchonia Corporation. Melbourne, FL). Violet light is primarily absorbed by flavoproteins [16] which mediates a wide array of biological processes such as bioluminescence, quenching of oxidative stress-induced radicals, DNA repair, and apoptosis [17] Red light is absorbed by cytochrome $\mathrm{C}$ oxidase which increases mitochondrial enzyme activity and subsequent ATP production [18]. Photo-acceptor molecules are similar to drug receptors. Following administration, the drug typically binds to a specific receptor on the cell wall and influences intracellular activity. Laser Pharmacology ${ }^{\mathrm{TM}}$ targets specific photoreceptor(s) within cells that are capable of influencing a diverse downstream cascade to produce a similar "drug-like effect."

With respect to treating onychomycosis, the $635 \mathrm{~nm}$ (red) diode has been shown to activate IL10 and PI3 kinase/eNOS signaling pathways, producing the powerful vasodilator Nitric Oxide (NO). Nitric oxide promotes endothelial cell migration and neovascularization [19]. The $405 \mathrm{~nm}$ (violet) diode has demonstrated the ability to activate flavoproteins, thereby upregulating the production of Reactive Oxygen Species (ROS) leading to the generation of hydrogen peroxide, hypochlorous acid, and hydroxyl radicals [20]. Another potential phototarget for the $405 \mathrm{~nm}$ wavelength is nicotinamide adenine dinucleotide phosphate oxidase (NOX) which also generates ROS [21]. NOX transfers electrons from cytosolic NADPH to Flavin Adenine Dinucleotide (FAD) and extracellular molecular oxygen to generate superoxide. Stimulation of NOX provides two benefits: phagocytes activation and exposing susceptible dermatophytes to the toxic effects of ROS.

The Laser Pharmacology ${ }^{\mathrm{TM}}$ effect in relation to treating onychomycosis, is produced by the combination of the red and violet wavelengths. Peroxynitrite, a potent and proven antifungal agent is formed following the simultaneous exposure to ROS (violet light) and NO (red light). When targeting fungal colonies, increased peroxynitrite has powerful cytotoxic effects, reducing the number of fungal pathogens [22]. Peroxynitrite was found to be more potent than hydrogen peroxide in oxidizing thiols, and induced heat shock proteins (Hsp70) and enhanced the ubiquitination of proteins [23]. Peroxynitrite is a potent stressor in yeast, inducing oxidative damage and protein nitration. In a separate study, Weller et al. (2001) demonstrated the antimicrobial effects of peroxynitrite on dermatophytic fungi, yeast, and bacteria [24]. The authors concluded that peroxynitrite is a novel antimicrobial agent for the eradication of skin pathogens [24].

Non-thermal lasers must not be associated with thermal lasers as the mechanism of action is completely different. Thermal lasers rely on heat transfer to fungal mycelium, reaching fungicidal temperatures of $43^{\circ} \mathrm{C}$ to $51^{\circ} \mathrm{C}$ for $2-4$ minutes, while lower temperatures can stimulate fungal growth [25].

A previous retrospective study demonstrated the safety and efficacy of the Lunula Laser device leading to FDA 510(k) market clearance for the temporary increase of clear nail in patients with onychomycosis caused by dermatophytes (e.g., Trichophyton rubrum and T. mentagrophytes) and/or yeasts (e.g., Candida albicans) (Erchonia Corporation. Melbourne, FL) [26]. The FDA market clearance was based on 100 retrospectively evaluated great toenails at baseline (pre-procedure administration) and 6 months post-procedure (study endpoint). The purpose of this clinical study is to further demonstrate the efficacy of mycological and complete cure rate of the Lunula nonthermal laser for the treatment of onychomycosis of the toenail.

\section{Methods}

\section{Study subjects}

The study was conducted in Mesa, Arizona at the Arizona Institute of Footcare Physicians. Mesa, has a hot desert type of climate, classified as BWh by the Köppen-Geiger system. In Mesa, the average annual temperature is $21.3{ }^{\circ} \mathrm{C}$, with rainfall around $221 \mathrm{~mm}$ per year. All twenty $(\mathrm{n}=20)$ subjects were recruited from among the investigators' pool of patients and individuals responding to local recruitment flyers. Subjects with onychomycosis of the great toenail completed a mycological elevation at the study site to confirm a positive mycological culture for Trichophyton rubrum or other common

Citation: Zang K, Sammons TM, Shanks S (2021) Treatment of Toenail Onychomycosis using Laser Pharmacology ${ }^{\mathrm{TM}}$. Int J Dermatol Clin Res 7(1): 001-006. DOI: https://dx.doi.org/10.17352/2455-8605.000040 
types of dermatophyte and clinical involvement of 20 to $50 \%$ of the target toenail. Subjects agreed to refrain from applying non-study treatments for their toenail onychomycosis and nail cosmetics such as clear or colored nail lacquers throughout the study.

\section{Study device}

The treatment device is a dual-diode laser (Erchonia ${ }^{\circledR}$ Lunula Laser ${ }^{\circledR}$; Erchonia Corporation. Melbourne, FL) employing wavelengths of $635 \mathrm{~nm}$ and $405 \mathrm{~nm}$ which are classified by the Center for Devices and Radiological Health as Class II laser diodes. The device has been previously FDAcleared for the temporary increase of clear nail in patients with onychomycosis.

\section{Procedure}

The affected toenails were treated with the laser for 12-minute sessions, weekly for 4 weeks, then one session at 3, 5, 7, 9 and 11 months. Study assessments were completed at $3,5,7,9,11,12$ and 14 months and included digital images, measurement of clear nail length, percent of onychomycosis involvement, and mycological evaluation. Mycological testing was completed using an enriched dermatophyte medium for detecting dermatophytes from clinical specimens (InTray ${ }^{\mathrm{TM}}$ DM; Biomed Diagnostics, Inc., White City, OR). Mycological testing was completed at end of Week 4 and months 3, 5, 7, 9, 11 , and 14

\section{Outcome measures}

Individual Responders were subjects achieving Complete Cure at 12 months post-treatment having satisfied Clinical Cure and Mycological Cure criteria. Clinical Cure was defined as $a \geq 12 \mathrm{~mm}$ increase in clear nail with evidence of distal growth of the affected area at 12 months, or complete clearance after 12 months if $<12 \mathrm{~mm}$ distal nail was involved prior to treatment. Mycologic Cure is defined as a negative culture for onychomycosis. Overall Study Success was defined as a $\geq 70 \%$ Clinical Cure rate and $\geq 80 \%$ Mycological Cure rate among those toenails at 12 months.

The 12-month secondary endpoints were Clinical Efficacy, defined as $<10 \%$ of affected target nail area, Mycological Cure, and unaffected New Nail Growth, defined as the change in baseline healthy nail measurement.

\section{Statistical analysis}

As enrolled subjects completed all study visits and assessments, only the ITT analysis was performed for primary outcome study success evaluation. A one-way analysis of variance for correlated samples was conducted to evaluate the significance of mean changes in study endpoints. A subsequent Tukey HSD analysis was used to determine significant changes in study endpoints at each time point.

\section{Ethics}

All subjects provided written informed consent prior to participating in any study-related activities. The protocol and related material used in this study was approved by a commercial investigational review board (Western Institutional Review Board ${ }^{\circledR}$, Puyallup, WA) and conformed to the good Clinical Practice guidelines of the International Conference on Harmonization. ClinicalTrials.gov Identifier NCT03066336.

\section{Results}

Enrolled subjects were female $(n=14,70 \%)$ and male $(n=6$, $30 \%$ ) with a mean (SD) age of 59.9 (8.9) years. All subjects $(100 \%)$ were Caucasian. Three subjects were taking systemic medications for hypertension, diabetes, and hypothyroidism. Affected great toenails were located on the right $(n=11,55 \%)$ and left foot $(n=9,45 \%)$. Two subjects recorded trying prior treatment approaches to manage their onychomycosis, which included one subject applying tree oil for a duration of 6 months and another subject applying nail lacquer for an unknown duration. Using a 1 to 5 scale to perceive effectiveness, with $1=$ not at all effective and 5= very effective, both subjects perceived their prior treatment approaches as "not at all effective". The mean duration of toenail onychomycosis was 24.4 (20.2) months (range, 4 to 60 months; $n=19$ ). One outlier of 120 months was excluded. At the baseline evaluation, mean clear nail measurement of the study great toenail was 6.7 (1.8) $\mathrm{mm}$ and the overall mean area of clinical onychomycosis involvement of the great toenail was 40.9 (11.1) \%.

A Clinical Cure was achieved for $14(70 \%)$ of the treated great toenails while a Mycological Cure was attained for 19 (95\%) great toenails. A Complete Cure was attained for 14 $(70 \%)$ of the study treated great toenails. Among the 14 subjects who attained Clinical Cure, all (100\%) also demonstrated Mycological Cure. Therefore, the Overall Study Success criteria was met, and overall study success was demonstrated.

The 12-month secondary endpoint of Clinical Efficacy was met by $18(90 \%)$ toenails, Mycological Cure Rate was attained by $19(95 \%)$ toenails and unaffected New Nail Growth, was attained by $20(100 \%)$ toenails ( $\mathrm{p}<0.0001)$. The mean 12 -month Clinical Cure rate was $70 \%$ and the Mycological Cure rate was 95\% (Table 1). Improvements were apparent beginning 3 months following the initial treatment phase and persisted throughout the study.

The mean (SD) extent of clinical onychomycosis involvement decreased from 40.9 (11.1) \% at baseline to 2.6 (7.0) \% at 12 months $(\mathrm{p}<0.0001)$ (Table 2$)$. The mean measure of clear nail increased from $6.7(1.8) \mathrm{mm}$ at baseline to 7.9 (1.9) at the end of treatment and $13.9(2.3) \mathrm{mm}$ at 12 months (Table 3). This decrease in nail involvement was significant at 3 months $(\mathrm{p}<0.005)$ and each subsequent time point $(\mathrm{p}<0.0001)$. The number of treated nails with negative mycology cultures increased from five (25\%) at the end of treatment to 19 (95\%) at 12 months (Table 4).

\section{Discussion}

A previous retrospective study assessed the results of three nonrandomized, open-label studies using the same 635

Citation: Zang K, Sammons TM, Shanks S (2021) Treatment of Toenail Onychomycosis using Laser Pharmacology ${ }^{\mathrm{TM}}$. Int J Dermatol Clin Res 7(1): 001-006. 
Table 1: Clinical and Mycological Cure Rates.

\begin{tabular}{|c|c|c|c|c|c|c|c|c|}
\hline & \multirow{2}{*}{ End of Treatment } & \multicolumn{7}{|c|}{ Months after Treatment, $\mathbf{n}(\%)$} \\
\hline & & 3 & 5 & 7 & 9 & 11 & 12 & 14 \\
\hline Clinical Cure & $0(0)$ & $2(10)$ & $5(25)$ & $3(15)$ & $3(15)$ & $7(35)$ & $14(70)$ & $12(60)$ \\
\hline Mycological Cure & $5(25)$ & $12(60)$ & $15(75)$ & $20(100)$ & $17(85)$ & $19(95)$ & $19(95)$ & $19(95)$ \\
\hline
\end{tabular}

Table 2: Clinical Onychomycosis Involvement.

\begin{tabular}{|c|c|c|c|c|c|c|c|c|c|}
\hline & \multirow{2}{*}{ Baseline } & \multirow{2}{*}{ End of Treatment } & \multicolumn{7}{|c|}{ Months after Treatment } \\
\hline & & & 3 & 5 & 7 & 9 & 11 & 12 & 14 \\
\hline Mean Percent (SD) & $\begin{array}{c}40.9 \\
(11.1)\end{array}$ & $\begin{array}{c}33.9 \\
(11.5)\end{array}$ & $\begin{array}{c}19.9 \\
(15.4)\end{array}$ & $\begin{array}{c}14.8 \\
(13.6)\end{array}$ & $\begin{array}{c}14.1 \\
(14.8)\end{array}$ & $\begin{array}{c}12.5 \\
(16.1)\end{array}$ & $\begin{array}{c}5.6 \\
(7.1)\end{array}$ & $\begin{array}{c}2.6 \\
(7.0)\end{array}$ & $\begin{array}{c}2.9 \\
(9.0)\end{array}$ \\
\hline
\end{tabular}

The decrease in baseline involvement was significant at each time point $(p<0.0001)$. (Tukey's HSD test).

Table 3: Clear Nail Measurement.

\begin{tabular}{|c|c|c|c|c|c|c|c|c|c|}
\hline & \multirow{2}{*}{ Baseline } & \multirow{2}{*}{ End of Treatment } & \multicolumn{7}{|c|}{ Months after Treatment } \\
\hline & & & 3 & 5 & 7 & 9 & 11 & 12 & 14 \\
\hline Mean, mm (SD) & $\begin{array}{c}6.7 \\
(1.8)\end{array}$ & $\begin{array}{c}7.9 \\
(1.9)\end{array}$ & $\begin{array}{l}10.1 \\
(2.6)\end{array}$ & $\begin{array}{l}11.3 \\
(3.3)\end{array}$ & $\begin{array}{l}11.2 \\
(2.9)\end{array}$ & $\begin{array}{l}11.2 \\
(3.0)\end{array}$ & $\begin{array}{l}12.2 \\
(3.4)\end{array}$ & $\begin{array}{l}13.9 \\
(2.3)\end{array}$ & $\begin{array}{l}13.8 \\
(2.2)\end{array}$ \\
\hline
\end{tabular}

The decrease in baseline involvement was significant at 3 months $(p<0.005)$ each subsequent time point $(p<0.0001)($ Tukey's HSD test).

Table 4: Percent Negative Mycology Cultures Across Study Evaluation

\begin{tabular}{|c|c|c|c|c|c|c|c|c|}
\hline & \multirow{2}{*}{ End of Treatment } & \multicolumn{7}{|c|}{ Month after Treatment } \\
\hline & & 3 & 5 & 7 & 9 & 11 & 12 & 14 \\
\hline Negative Mycology Culture, n (\%) & $\begin{array}{c}5 \\
(25)\end{array}$ & $12(60)$ & $15(75)$ & $20(100)$ & $17(85)$ & $19(95)$ & $19(95)$ & $19(95)$ \\
\hline
\end{tabular}

Table 5: Comparison of Complete Cure and Mycologic Cure.

\begin{tabular}{|c|c|c|c|c|c|}
\hline & \multirow{2}{*}{$\begin{array}{c}\text { Laser Pharmacology }^{\mathrm{TM}} \\
\text { Present Study }\end{array}$} & \multicolumn{2}{|c|}{ Topical Antifungals } & \multicolumn{2}{|c|}{ Oral Antifungals } \\
\hline & & Efinaconazole $^{10}$ & Tavaborole $^{31}$ & Terbinafine $^{29}$ & Itraconazole ${ }^{29}$ \\
\hline Complete Cure (\%) & 70 & $15.2-17.8$ & $6.5-9.1$ & 78 & 30 \\
\hline Mycologic Cure (\%) & 95 & $53.4-55.2$ & $31.1-35.9$ & 50 & 46 \\
\hline
\end{tabular}

$\mathrm{nm} / 405 \mathrm{~nm}$ dual-diode device to treat onychomycosis of the great toenail [26]. In that report, affected toenails $(N=100)$ were treated for 12 minutes weekly for 2 or 4 weeks and assessed after 6 months. Most treated toenails (67\%) achieved treatment success defined as achieving $\geq 3 \mathrm{~mm}$ of clear nail growth and the extent of clear nail at baseline increased by a mean of $5.18(4.76) \mathrm{mm}$ after 6 months $(\mathrm{p}<0.0001)$. There were no adverse events.

In the current study, subjects were treated more aggressively with four weekly 12-minute treatment sessions followed by five subsequent bimonthly treatments. The 12-month Clinical Cure rate was $70 \%$ and the Mycological Cure rate was $95 \%$. The results compare favorably with the mycological/complete cure rate of the topical antifungal agent's tavaborole (30-36\%/6$10 \%$ ) [27] and efinaconazole (53.4-55.2\%/15.2-17.8\%) [28] which require daily application for 48 weeks, and mycological/ clinical cure rates of the oral antifungal agent's terbinafine (78\%/50\%), and itraconazole (46\%/30\%) [29] (Table 5). Disadvantages of systemic antifungals is drug toxicity. The use of systemic antifungal, itraconazole, has reported adverse effects in $2-39 \%$ of patients, with the most common being gastrointestinal disturbances such as mild diarrhea, nausea, abdominal pain, and vomiting [30]. Furthermore, it is essential for healthcare professionals to consider drug to drug interactions when prescribing itraconazole, as many other drugs are metabolized by the same cytochrome (P450 3A4) enzyme in the liver.

Currently, a 12-week course of oral terbinafine is considered the gold standard for the treatment of onychomycosis [25]. However, the complete cure rate at 36 weeks after the completion of terbinafine in the original approval study was reported to be only $38 \%$. Results from this clinical trial demonstrated the Lunula Laser produced a greater mycological and complete cure rate than previously FDA approved topical and systemic drugs Figures 1-3.

\section{Conclusion}

This study confirms the safety and effectiveness of a non-thermal $635 \mathrm{~nm} / 405 \mathrm{~nm}$ dual-diode laser device for the treatment of onychomycosis-infected toenails following four weekly and five bi-monthly treatment sessions. This article presents data from the first completed test site of an ongoing multi-site clinical trial, further data is warranted.

\section{Acknowledgment}

All authors contributed equally to writing the manuscript. The authors acknowledge the editorial assistance of Dr. Carl S. Hornfeldt, Apothekon, Inc., during the preparation of this manuscript. The study was sponsored by Erchonia Corporation, Melbourne, FL. As the study sponsor, Erchonia 
was responsible for device setup and training. The study was performed at an independent physician site, which completed CITI training (Collaborative Institutional Training Initiative) and was approved through the Western Institutional Review Board (study reference \# \#20171235). Dr. Kerry Zang has no competing interests and was not provided any compensation for his participation in the clinical trial. Travis Sammons and Steve Shanks are employees of Erchonia Corporation (Study Sponsor). Statistical analysis of the clinical data was performed by Regulatory Insight, Inc. Elvira Walls, MS, who was the independent statistician for this clinical investigation.

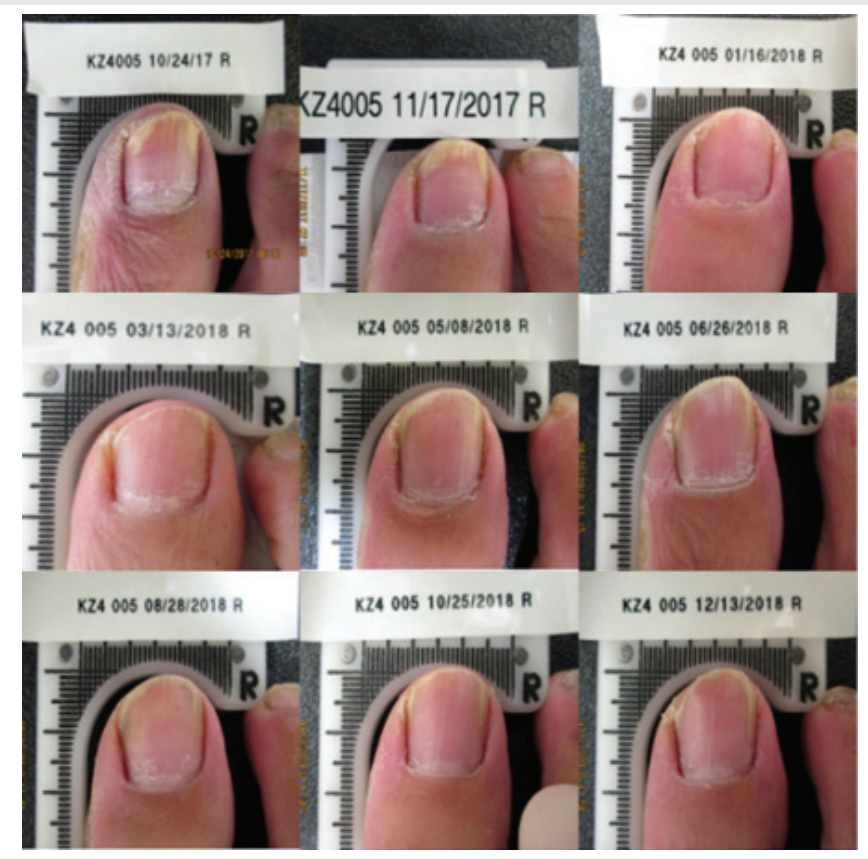

Figure 1: Change in Onychomycosis Condition After 14 months. This 43 year-old female subject had onychomycosis of the great toe for 60 months prior to treatment.

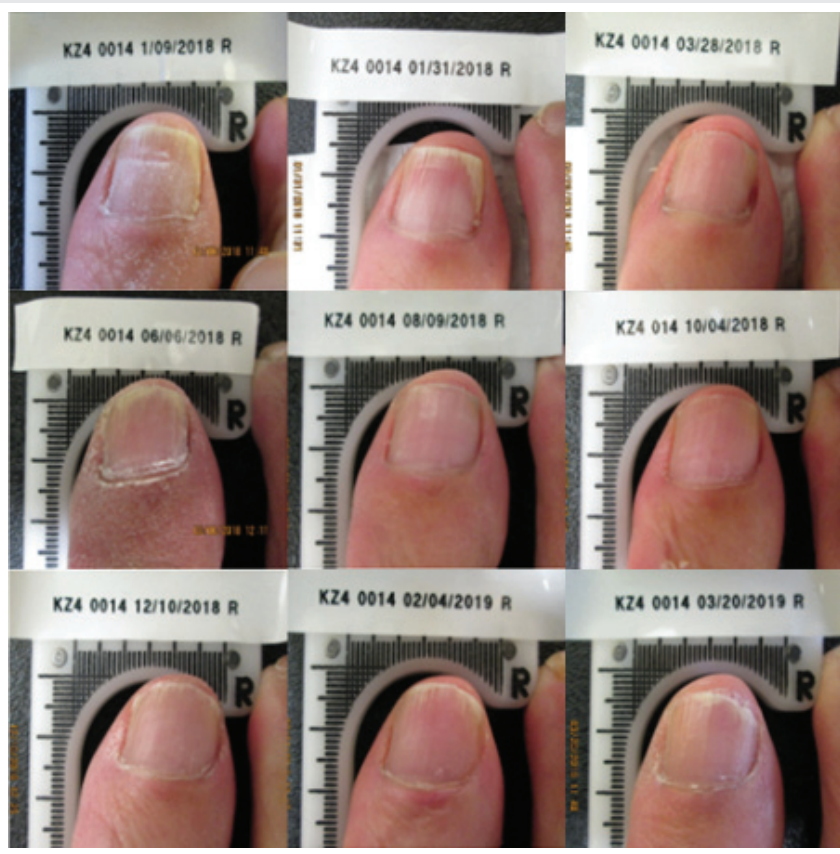

Figure 2: Change in Onychomycosis Condition After 15 months. This 72 year-old male subject had onychomycosis of the great toe for 4 months prior to treatment.

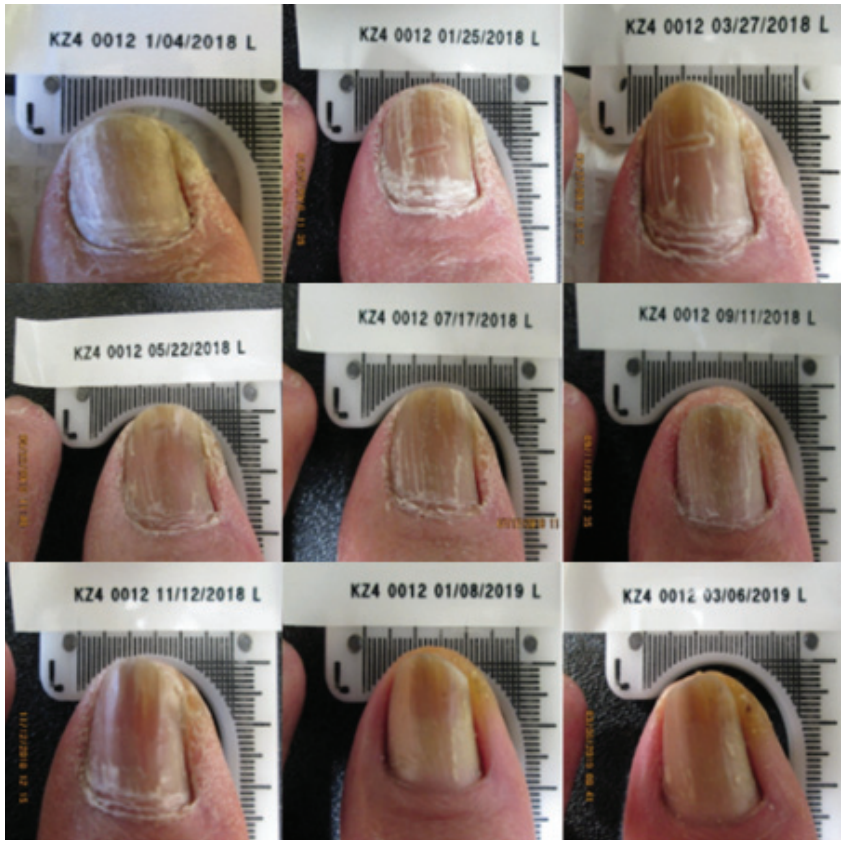

Figure 3: Change in Onychomycosis Condition After 15 months. This 58 year-old female subject had onychomycosis of the great toe for 4 months prior to treatment.

\section{References}

1. Gupta AK, Stec N, Summerbell RC, Shear NH, Piguet V, et al. (2020) Onychomycosis: a review. J Eur Acad Dermatol Venereol 34: 1972-1990. Link: https://bit.ly/3otqbyf

2. Tosti A, Hay R, Arenas-Guzmán R (2005) Patients at risk of onychomycosis-risk factor identification and active prevention. J Eur Acad Dermatol Venereol19: 13-16. Link: https://bit.ly/3pv2Eyr

3. Gupta AK, Mays RR (2018) The impact of onychomycosis on quality of life: a systematic review of the available literature. Skin Appendage Disord 4: 208216. Link: https://bit.ly/3t3gFFE

4. Stewart CR, Algu L, Kamran R, Leveille CF, Abid K, et al. (2020) Impact of onychomycosis and treatment on patient reported quality of life outcomes: a systematic review. J Am Acad Dermatol S0190-9622:31020-31023. Link: https://bit.ly/36ocf2l

5. Kayarkatte MN, Singal A, Pandhi D (2020) Impact of onychomycosis on the quality of life: dermatology life quality index-based cross-sectional study. Skin Appendage Disord 6: 115-119. Link: https://bit.ly/3qYDAQA

6. Ghannoum MA, Hajjeh RA, Scher R, Konnikov N, Gupta AK, et al. (2000) A largescale North American study of fungal isolates from nails: the frequency of onychomycosis, fungal distribution, and antifungal susceptibility patterns. $J$ Am Acad Dermatol 43: 641-648. Link: https://bit.ly/2MbO4NG

7. Aggarwal R, Targhotra M, Kumar B, Sahoo PK, Chauhan MK (2020) Treatment and management strategies of onychomycosis. J Mycol Med 30: 100949 Link: https://bit.ly/3iXgpDq

8. Aggarwal R, Targhotra M, Sahoo P.K, Chauhan MK (2020) Onychomycosis: Novel Strategies for Treatment. J Drug Deliv Sci Tec 25: 101774. Link: https://bit.ly/3advOvt

9. Aggarwal R, Targhotra M, Kumar B, Sahoo PK, Chauhan MK (2020) Novel Polypseudorotaxanes Hydrogel based Nail Lacquer of Efinaconazole for Transungual Drug Delivery. Drug Deliv Lett 10: 1-10. Link: https://bit.ly/36lHv25

10. Jublia ${ }^{\circledR}$ (efinaconazole) topical solution for topical use [Prescribing Information. Bausch Health US, LLC, Bridgewater, NJ. 
11. Berry TS, Quarneri PJ, Roche G, Sammons TM (2020) A randomized, doubleblind, sham-controlled study evaluating the effectiveness of a low-level laser device for treating lower back pain. eMedical Research 2: 1-12.

12. Roche GC, Murphy DJ, Berry TS, Shanks S (2016) Low-level laser therapy for the treatment of chronic neck and shoulder pain. Funct Neurol Rehabil Ergon 6: 97-104. Link: https://bit.ly/2KX1kVS

13. Jastifer JR, Catena F, Doty JF, Stevens F, Coughlin MJ (2014) Low-level laser therapy for the treatment of chronic plantar fasciitis: a prospective study. Foot Ankle Int 35: 566-571. Link: https://bit.ly/3cjOwUX

14. Jackson RF, Roche G, Mangione T (2009) Low-level laser therapy effectiveness for reducing pain after breast augmentation. Am J Cosmet Surg 26: 1-5. Link: https://bit.ly/36mfHKK

15. Roche GC, Jackson RF, Holsey LJ, Shanks S (2017) Low-level laser therapy for reducing the hip, waist, and upper abdomen circumference of individuals with obesity. Photomed Laser Surg 35: 142-149. Link: https://bit.ly/36mBcvj

16. Hamblin MR (2018) Mechanisms and mitochondrial redox signaling in photobiomodulation. Photochem Photobiol 94: 199-212. Link: https://bit.ly/2YotNaf

17. Kushibiki T, Ishihara M (2017) Biological function of low reactive level laser therapy (LLLT). In Photomedicine - Advances in Clinical Practice. Link: https://bit.ly/3puprud

18. Hollis VS, Palacios-Callender M, Springett RJ, Delpy DT, Moncada S (2003) Monitoring cytochrome redox changes in the mitochondria of intact cells using multi-wavelength visible light spectroscopy. Biochim Biophys Acta 1607: 191-202. Link: https://bit.ly/3afMQJk

19. Wang L, Hu L, Grygorczyk R, Shen X, Schwarz W (2015) Modulation of extracellular ATP content of mast cells and DRG neurons by irradiation: studies on underlying mechanism of low-level-laser therapy. Mediators Inflamm 2015 630361. Link: https://bit.ly/2NCA1kC

20. Snezhkina AV, Kudryavtseva AV, Kardymon OL, Savvateeva MV, Melnikova NV, et al. (2019) ROS Generation and antioxidant defense systems in normal and malignant cells. Oxid Med Cell Longev 2019: 6175804. Link: https://bit.ly/3onE3dq

21. Ramakrishnan P, Maclean M, MacGregor SJ, Anderson JG, Grant MH (2016)
Cytotoxic responses to $405 \mathrm{~nm}$ light exposure in mammalian and bacterial cells: involvement of reactive oxygen species. Toxicol In Vitro 33: 54-62. Link: https://bit.ly/36mltvX

22. Warris A, Ballou ER (2019) Oxidative responses and fungal infection biology Semin Cell Dev Biol 89: 34-46. Link: https://bit.ly/3pupYfH

23. Buchczyk DP, Briviba K, Hartl FU, Sies H (2000) Responses to peroxynitrite in yeast: glyceraldehyde-3-phosphate dehydrogenase (GAPDH) as a sensitive intracellular target for nitration and enhancement of chaperone expression and ubiquitination. Biol Chem 381: 121-126. Link: https://bit.ly/3afNg2m

24. Weller R, Price RJ, Ormerod AD, Benjamin N, Leifert C (2001) Antimicrobia effect of acidified nitrite on dermatophyte fungi, Candida and bacterial skin pathogens. J Appl Microbiol 90: 648-652. Link: https://bit.ly/3iV5qdl

25. Kawa N, Lee KC, Anderson RR, Garibyan L (2019) Onychomycosis: a review of new and emerging topical and device-based treatments. J Clin Aesthet Dermatol 12: 29-34. Link: https://bit.ly/3ots4LI

26. Zang K, Sullivan S, Shanks S (2017) A retrospective study of non-thermal lase therapy for the treatment of toenail onychomycosis. J Clin Aesthet Dermato 10: 24-30. Link: https://bit.ly/36ktyRo

27. Elewski BE, Aly R, Baldwin SL, González Soto RF, et al. (2015) Efficacy and safety of tavaborole topical solution, $5 \%$, a novel boron-based antifungal agent, for the treatment of toenail onychomycosis: Results from 2 randomized phase-III studies. J Am Acad Dermatol 73: 62-69. Link: https://bit.ly/39tiCDK

28. Gupta AK, Elewski BE, Sugarman JL, leda C, Kawabata H, et al. (2014) The efficacy and safety of efinaconazole $10 \%$ solution for treatment of mild to moderate onychomycosis: a pooled analysis of two phase 3 randomized trials. J Drugs Dermatol 13: 815-820. Link: https://bit.ly/36nuNQf

29. Sigurgeirsson B, Olafsson JH, Steinsson JB, Paul C, Billstein S, et al. (2002) Long-term effectiveness of treatment with terbinafine vs itraconazole in onychomycosis: a 5-year blinded prospective follow-up study. Arch Dermatol 138: 353-329. Link: https://bit.ly/3crDgGd

30. Kurn H, Wadhwa R (2020) Itraconazole. In: StatPearls. StatPearls Publishing Treasure Island (FL).

31. Kerydin® (tavaborole) topical solution 5\%. [Prescribing Information, 2018] Pfizer Labs, Division of Pfizer Inc, NY, NY.

\section{Discover a bigger Impact and Visibility of your article publication with}

\section{Peertechz Publications}

\section{Highlights}

* Signatory publisher of ORCID

* Signatory Publisher of DORA (San Francisco Declaration on Research Assessment)

* Articles archived in worlds' renowned service providers such as Portico, CNKI, AGRIS, TDNet, Base (Bielefeld University Library), CrossRef, Scilit, J-Gate etc.

* Journals indexed in ICMJE, SHERPA/ROMEO, Google Scholar etc.

* OAI-PMH (Open Archives Initiative Protocol for Metadata Harvesting)

* Dedicated Editorial Board for every journa

* Accurate and rapid peer-review process

* Increased citations of published articles through promotions

* Reduced timeline for article publication

Submit your articles and experience a new surge in publication services (https://www.peertechz.com/submission).

Peertechz journals wishes everlasting success in your every endeavours.

Copyright: ๑ 2021 Zang K, et al. This is an open-access article distributed under the terms of the Creative Commons Attribution License, which permits unrestricted use, distribution, and reproduction in any medium, provided the original author and source are credited.

Citation: Zang K, Sammons TM, Shanks S (2021) Treatment of Toenail Onychomycosis using Laser Pharmacology ${ }^{\text {Tw. }}$. Int J Dermatol Clin Res 7(1): 001-006. DOI: https://dx.doi.org/10.17352/2455-8605.000040 